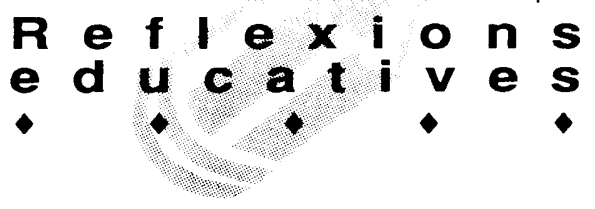

\title{
LA LOGSE I LA CONVERGĖNCIA AMB EUROPA
}

Hem d'acceptar que el país porta un temps, pràcticament des de 1985, que ha trencat allò que hom va anomenar l'esperit de la transició. Transició que en els darrers temps ha portat alguns demócrates a un cert desencis, no exempt d'una visió cínica, on si és veritat que el país avança -i fins i tot és possible que pugui convergir amb Europa-, hom s'haurà de preguntar a quin preu. Al preu que el PSOE, Partit Socialista Obrer Espanyol, sigui cada vegada el més espanyol i menys socialista i obrer, i això ho diem sense cap to pejoratiu, solament com a constatació d'una realitat objectivable.

L'esquerra més clàssica, el PCE, Partit Comunista d'Espanya, ha perdut les seves senyes d'identitat i té una tremenda i sistemàtica vocació de marginalitat que està confegint de pressa i corrents un nou model de relacions politiques, Izquierda Unida, que no acaba de trobar els seus marcs de referència, perduts en disputes i picabaralles.

Una dreta que només encerta, amb un cert nombre d'electors, a força de ser nacionalistes sentimentals en els seus discursos regionalistes i autonòmics, i juguen a la política de l'Estat Central en tots els altres aspectes. I la dreta pura i dura, la qual segueix defensant els valors eterns de l'Espanya imperial es debat entre ésser homologable amb les dretes europees i estar en una política d'encalçar i abatre el govern, a despit de posar en ocasions en perill la pròpia identitat de la democràcia per les seves declaracions altisonants i demagògiques.

Els sindicats, obstinats a mantenir un discurs fora del context europeu i entossudits en un paper polític que cap altre estament social està assumint per incapacitat, tot portant el seu propi sindicalisme a un cul de sac; res no hi ha tan frustrant com veure una $i$ altra vegada que les vagues generals, per a l'única cosa que serveixen és per arrencar alguns vots al govern, que continua guanyant eleccions i governant.

Davant d'aquesta situació ens trobem amb una Lleid'Ordenació General del Sistema Educatiu, LOGSE, que desitja preparar la joventut i el país per a Europa, però que en la realitat de la nostra professió, magisteri, observem com tot alló que deia defensar ho està llençant per la borda, en minimitzar el paper de la labor educativa, menyspreant la qualitat professional de les Escoles de Magisteri i legislant, en els projectes que es coneixen per modificar la Llei de Reforma Universitària, amb una visió matussera d'allò que significa l'educació com a procés de personalització de l'ésser humà, que requereix uns profesionals que no siguin únicament tècnics trets per solucionar problemes concrets, sinó persones, professionals que amb una visió de futur s'enfrontin als reptes del món modern, que ningú no sap com serà d'aquí a quinze anys.

Sens dubte que, per als qui hi arriben d'altres indrets, principalment del tercer món i d'Amèrica llatina (i el nostre país darrerament és visitat per força personalitats, som al 1992, any carismàtic per antonomàsia), el simple fet de disposar d'un mètode plausible i civilitzat com la democràcia per dirimir els conflictes representa un desideratum envejable. Però per als qui hi vivim, allò que més destaca davant els nostres ulls és que la democràcia no implica automàticament llibertat, igualtat i fraternitat.

En ocasions trobem a faltar, com diu Victòria Camps (1990), que: "Per la seva importància, la justícia és més que una simple virtut, ja que ha de materialitzar-se, per ser eficaç i operativa, en una legislació, en unes institucions. La justícia -els drets de la igualtat i de la llibertat- és aquell telos oficap a la qual hauria de tendir la societat democràtica, i no pot reduir-se a una qualitat o manera de ser dels individus. La seva forma de ser justos consistirà, pel contrari, a lluitar per unes lleis i unes institucions justes".

Això ens porta a acceptar que en ocasions també ho ha assenyalat Gregorio Morán (1992), existeix un divorci entre el que és públic i el que és privat, que al cap i a la fi és el truc essencial de la Democràcia Progressada i el que explica que aquell règim i no cap altre fos el destinat a l'èxit darrer en la dominació del poble.

Tot això ens porta a tenir en compte i fer nostra la situació com a educadors en afirmar, com assenyala Sotelo (1987), que en un curt espai -que no durarà gaire- en què la democràcia occidental no té competidor en el món -han quedat escombrats els dos gran rivals que li van sortir en aquest segle, el cabdillatge feixista i el burocratisme estalinista-, la tasca de l'intel.lectual, entès en el sentit més ampli de ciutadà que se sent corresponsable de la república, s'ha de centrar en la crítica de l'ordre establert, no des de criteris foranis, que han perdut tota credibilitat, sinó des dels mateixos supòsits i valors en què diu fonamentar-se la democràcia. Cal atrevir-se a prendre-la seriosament per deixar constància de l'abisme que separa principis de realitats.

Perquè llibertat i igualtat són els dos grans valors de la modernitat, la superioritat de la democrà- 


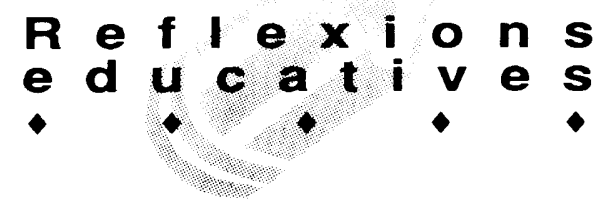

cia front al totalitarisme feixista $i$ front a l'anomenat "socialisme real" sembla, avui en dia, indiscutible. En aquest sentit, el Programa 2000 del PSOE hi proposa com a senyes d'identitat l'aprofundiment de la democràcia, d'acord amb els ideals pels quals sorgí i que li confereixen -almenys verbalment- legitimitat i desitjabilitat moral.

Però de fet les seves propostes i les realitzacions legislatives tendeixen a garantir la comoditat i la seguretat pública per damunt de qualsevol altre valor; en concret, haurien de desenvolupar el sentit de justícia a través d'una intervenció que assegurés la llibertat i la igualtat dins del reconeixement històric de l'home com a subjecte de la res pública, ja que quan el vertigen de la seguretat pública s'apodera d'una democràcia, els drets fonamentals, els inalienables drets de cada individu singular, entren en recessió. l'anomenada "beautiful people" d'entre els seus productes més característics.

La LOGSE, en lloc de contribuir a superar les desigualtats socials $\mathrm{i}$ advocar per un sentit de la justícia entesa com a conciliació entre la llibertat i la igualtat (Programa 2000), posa de manifest, amb arguments manllevats de l'economia política liberal, de la sociologia, de la genètica, de la crítica al marxisme, de la teoria elitista de la democràcia, una aposta per un individu possessiu, insolidari, d'acord amb la ideologia dominant del culte als diners. Situacions que ja han estat acceptades en la realitat político-pràctica $i$ de vegades denunciades per membres del PSOE. Rodríguez López (1990) afirma: "El socialisme democràtic ha de canviar d'èmfasi, però no de finalitats. La igualtat segueix essent la utopia a aconseguir".

Igualtat en la llibertat, que ha de reposar en

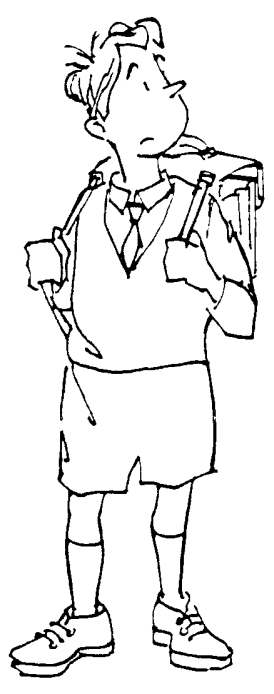

En l'actualitat, i a propòsit de la LOGSE, la política educativa del PSOE pretén d'ajustar el sistema educatiu als nous criteris del capitalisme postindustrial, tot endegant una política educativa que contribueix, per una banda, a reforçar la legitimació del sistema social, alhora que manté $i$ aprofundeix l'estratificació social en les seves desigualtats, i, per una altra banda, construint identitats que s'avinguin bé amb els esquemes valoratius i perceptius dels nous grups socials en ascens. Els especuladors financers $i$
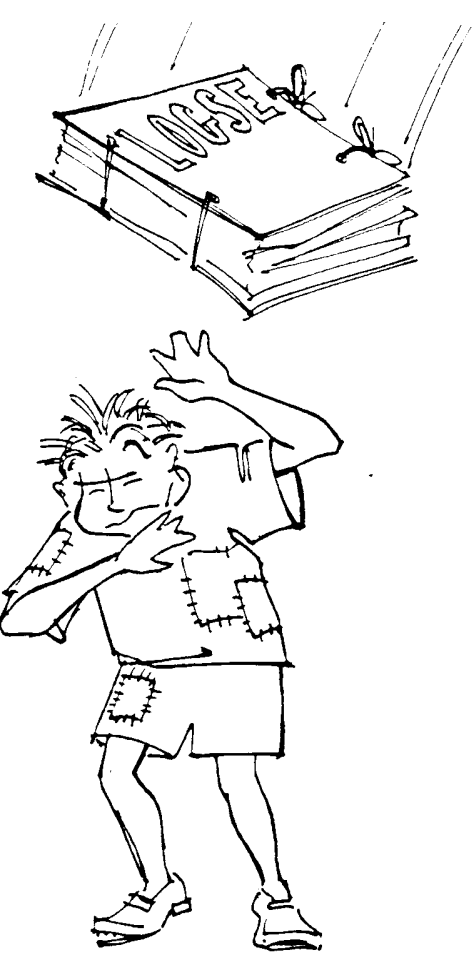

l'oposició despotisme-democràcia, i reconeixent que els règims democràtics liberals només són possibles, històricament, com a conseqüència d'un llarg treball previ que consistexi a "disciplinar" els seus ciutadans. És per això que la comprensió del procés de formació / producció de l'home modern disciplinat requereix una concepció que doni compte de la "naturalesa" del poder en una determinada societat $i$ en un determinat periode. Per aquesta raó no s'entén ni es pot comprendre la nova línia que el govern socialista desitja 


\section{ำ}

impulsar, tot rebaixant la professionalitat de les Escoles Universitàries de Formació del Professorat d'EGB a una categoria en la qual la docència tancada privi per damunt de la docència oberta i de la investigació docent. Tampoc no s'entenen gaire els nous plans $i$ els programes de les noves especialitats de magisteri on les matèries formatives fonamentals i estructurals han estat rebaixades significativament.

Nosaltres creiem que no s'ha de concebre l'individu com a "víctima", sinó com una construcció del funcionament del poder. És una construcció com les altres, i els "ciutadans", amb els seus detalls personals, no són res més que una sèrie entre d'altres. En $\mathrm{fi}$, sorgeixen en un camp de batalla.

És reconegut que l'ideal modern de democràcia va néixer com una crítica de la primitiva burgesia als privilegis feudals i com a cobertura ideològico-política del mercat. No obstant això, aquest ideal ha estat substituït per la idea de democràcia entesa com a govern d'èlites, a les quals els ciutadans concedeixen el poder de decidir, durant quatre anys. Aquesta concepció fomenta la desigualtat, front a l'essència igualitària de la democràcia, en convertir-la en un mecanisme per a decidir qui ha d'exercir el poder, i concretament en l'aplicació discriminada de la regla de les majories.

Liberals i socialdemòcrates defensen una ètica política que descansa en l'oposició capitalisme-socialisme i que té com a finalitat protegir i fomentar el consens existent; consens que renuncia a qualsevol intent de fonamentació de la democràcia, ja que certament les fonamentacions diferirien entre si i no serien sinó motiu de discòrdia, però en la realitat pràctica pretén "normativitzar" una idea de democràcia que operi similarment a un equilibri de mercat, en el benentès que els ciutadans s'hi comportin com a consumidors, i els politics com a empresaris que han de competir-hi pel vot. D'això se'n deriva que la democràcia s'esgoti en el principi de la majoria per selecccionar els qui l'obtenen, sense cap altra mena de control que aquell que exerceixen els ciutadans amb el seu vot cada quatre anys.

La democratització de la vida social ha quedat reduïda, doncs, a l'extensió del mecanisme d'elegir élites representants, tot fent ús de la regla de les majories. Mecanisme que contribueix a la "construcció gremial de la realitat" com Giner i Pérez Yruela (1979) I' han anomenat, i que reprodueix el feudalisme medieval; feudalisme, per descomptat, fonamentat en nom del principi de la majoria.

Feudalisme que emergeix quan l'individu es dissol en la corporació, ja que en sentir-se impotent per defendre els seus interessos s'alia amb altres individus que es troben en igual situació, fan jurament de vassallatge al grup -recordant actuacions feudalsi aquest els garanteix la satisfacció dels seus desitjos i la defensa contra l'enemic.

Aquest mecanisme, en lloc de produir individus autònoms, solidaris, implica convertir en massa els ciutadans, o més ben dit, l'emergència de la polaritat tribus / masses (Maffesoli, 1990) en oposició a la polaritat individu / societat.

El paradigma tribal de Maffesoli deixa clar no únicament la relació simbòlica que reestructura els nostres barris -s'ha de convenir que si "la tribu és la garantia de la solidaritat també por ser la font del racisme i de l'ostracisme pobletà" (quina explicació cal donar-li a la revolta dels barris perifèrics d'algunes ciutats espanyoles a l'octubre de 1991-, sinó que també, per una banda, la lògica del mercat que fa creure a la gent que els diners són quelcom de palpable i material, quan en realitat és l'abstracció de les abstraccions (Garcia Calvo, 1990), i per una altra, la lògica de la identitat que opera, en l'actualitat, i que apunta a construir "una personalitat" creativa, flexible adaptable, "crítica" però alhora de fet no conflictiva, comunicativa, sensible i polivalent, una "personalitat" adaptable al mercat de treball i a l'ambient polític. En definitiva, ¿es pot dir que ens trobem en una societat democràtica? ¿Societat vertebrada a l'entorn de pràctiques institucionals de construcció d'allò que és normal?

Tot fa veure que, amb l'ampliació de l'educació general bàsica, amb la prestació a tots els espanyols de l'ensenyament secundari, amb la reforma profunda de la formació professional i amb la millora de la qualitat de l'ensenyament, tot plegat, amb la nova doctrina d l'educació universal, es tracta de donar legitimitat a una societat sotmesa a l'imperialisme del mercat $i$ als seus corresponents poders constituïts.

Amb l'extensió del dret a l'educació en aquesta societat del futur, configurada com una societat del saber, com una societat educativa, en la qual tothom, al llarg de la seva vida, es troba a l'escola i / o en formació permanent, es tracta un altre cop més de la legitimació de la desigualtat social en virtut de les aptituds certificades per l'escola. L'accés al mercat de treball queda limitat i legitimat pels certificats que s'hi puguin aconseguir, amb la qual cosa una gran quantitat de joves cada vegada es trobaran més marginats, des del mateix moment de la seva entrada en aquest mercat. 


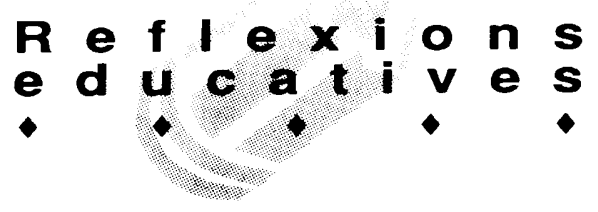

La LOGSE no afavoreix veritablement la democràcia, ja que no va en la direcció d'implantar una major llibertat i igualtat real, raó per la qual la seva filosofia ha estat classificada d'igualitarisme demagògic. I sota aquesta cobertura ideològica s'amaguen les relacions entre el sistema educatiu i la societat, o més aviat la relació de cada grup social amb el sistema educatiu i en el sistema educatiu, aixi com aquells processos socials que tenen lloc dins de les institucions del sistema educatiu (els seus centres, les etapes, els cicles i les pràctiques quotidianes).

Una llei que, en lloc d'afavorir un aprofundiment de la democràcia, és un instrument de legitimació de la sobirania popular establerta per la nostra Constitució, entesa aquesta com l'acceptació o rebuig de les élites. Élites que, d'acord amb el capítol VII del Llibre VI del Contracte Social de Rousseau, combreguen amb un substrat credencial comú (mercat, meritocràcia, competitivitat, individualisme, disciplina). Élites interessades, a fi de mantenir la seva hegemonia social, a imposar i inculcar la seva manera d'entendre el món i els seus estils de vida a través de l'escola, és clar, amb el respecte que cal "el ple desenvolupament de la personalitat de l'alumne".

Per tot això és necessari d'identificar la igualtat formal de la Constitució de 1978 amb la igualtat d'accés a la institució escolar, a fi i efecte que li correspongui establiruna justa adequació entre els mèrits -escolarment sancionats- i la posició social. D'aquesta manera la meritocràcia esdevé, o més aviat és, la nova religió mundial, religió que dóna legitimitat a les noves i a les velles élites en el poder.

Si la LOGSE manté l'estratificació social i fins i tot l'augmenta en les seves desigualtats, ja que només s'hi canvien els criteris que regeixen la producció, la qüestió rau a esbrinar si el camp educatiu, simbòlic i cultural funciona o no a partir d'imperatius democràtics d'igualtat $i$ justícia social.

Lerena (1986) va treballar sistemàticament aquest aspecte. Els seus treballs contribueixen a determinar les condicions històriques constitutives del camp de l'educació i de la cultura de la societat contemporània, tot descrivint l'estructura, l'organització i el funcionament de la dominació en la societat contemporània, i hi explica com darrere dels canvis del sistema d'ensenyament, des de 1970 (Llei General d'Educació) fins a 1990 (LOGSE, sense oblidar la LODE) hi ha la lògica pròpia dels moviments sòcio-econòmics de llarga durada (dels cicles llargs de l'economia de mercat). Lògica la cobertura ideològica de la qual rau en el mite de la igualtat d'oportunitats i del capital humà.
Lerena realitza una crítica racional i rigorosa de la ideologia dominant en el món de l'educació, crítica conseqüent amb la teoria del coneixement sociològic. Coneixement que no elabora nous mites a partir de la denúncia i l'enunciació, i que destaca el caràcter polític de l'educació, que mai no pot ser neutral. Paulo Freire escrivi encertadament: "L'ducació té naturalesa política en tot el món. En termes metafísics, la política és l'ànima de l'educació, la seva raó de ser, sigui en el primer món o en el tercer món. Quan un educador estudia una assignatura en particular (per exemple, quan Giroux analitza el currículum ocult) totes les instàncies educatives esdevenen actes polítics. Ni jo ni ningú pot, de cap manera, contradir això. Per tant, la naturalesa política de l'educació no és un exotisme de Paulo Freire, que pertany al Tercer Món".

És el nostre desig que aquesta lectura que hem fet de la LOGSE fos motiu de reflexió per als mestres iles mestres, a fi i efecte de determinar fins a quin punt ens trobem on es trobem, i som allò que som. Ells i elles decidiran.

Ignasi Brunet Icart, Sociologia de l'Educació Luis F. Valero Iglesias, Teoria i Història de l'Educació

\section{Bibliografia}

BRUNET ICART, I. , VALERO IGLESIAS, L. (1992): Hacia una economía política de la educación: Ia LOGSE, PPU, Barcelona.

GINER, S. (1979): Sociedad masa. Crítica del pensamiento conservador, Península, Barcelona.

CRUZ, M. (1991): Filosofía de la historia, Paidós, Barcelona.

CAMPS, V. (1990): Virtudes públicas, Espasa, Madrid.

SOTELO, I. (1987): "Universidad y política", en Educación y Sociología en España. Selección de Textos, Carlos Lerena Editor, Akal, Madrid.

MORAN, G. (1992): El precio de la transición, Planeta, Barcelona.

MAFFESOLI, M. (1990): El tiempo de las tribus, Icària, Barcelona.

LERENA, C, (1986): Escuela, ideología y clases sociales en España, Akal, Madrid.

RODRIGUEZ LOPEZ,F. (1990): "El socialismo democràtico y el programa 2000" en Leviatan, núm. 40, pàg. 17, Madrid. 